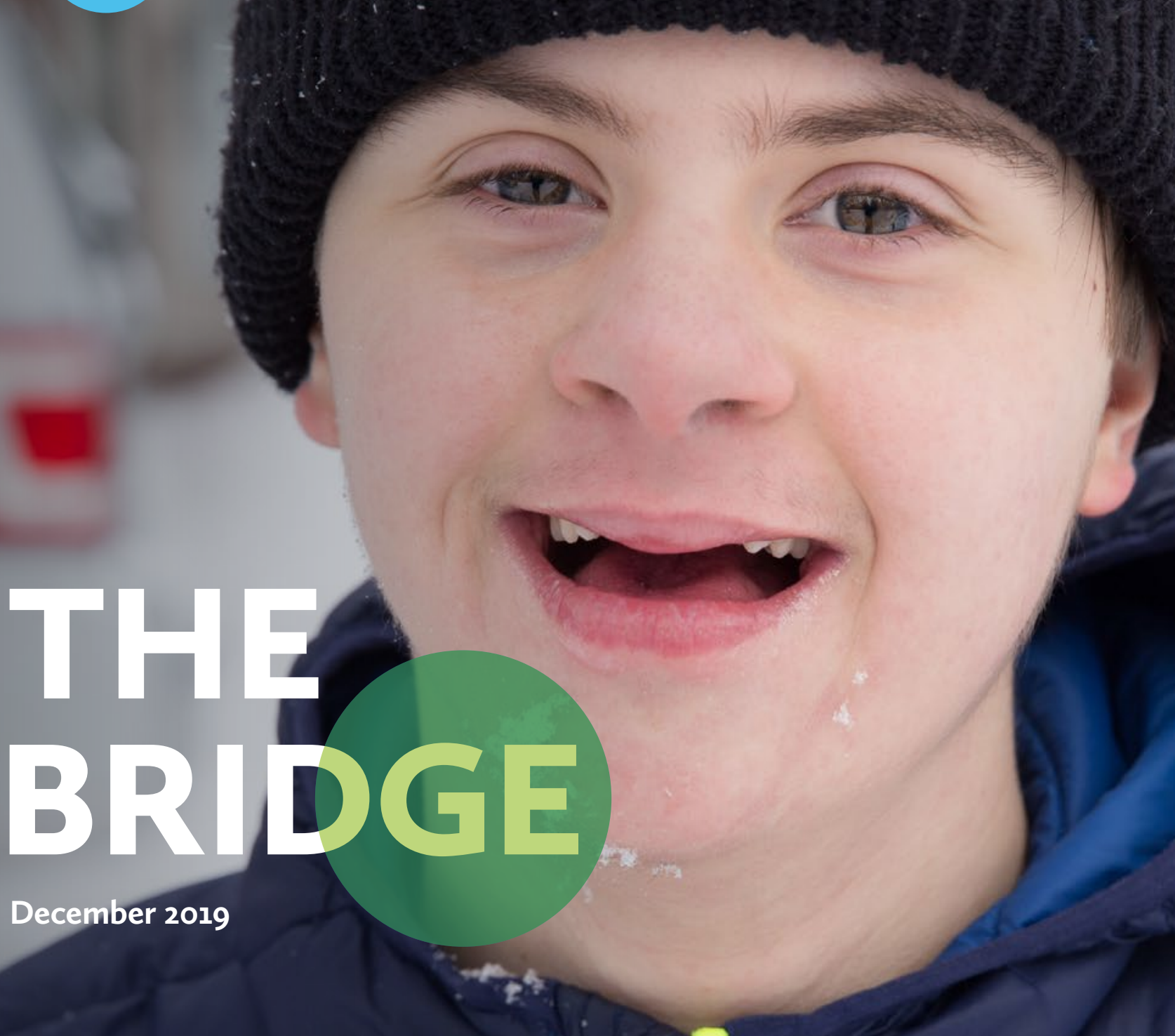

This issue covers recent research in: ASD, Anxiety, PTSD, Student well-being; Avoidance behaviours \& Noisy home environments.
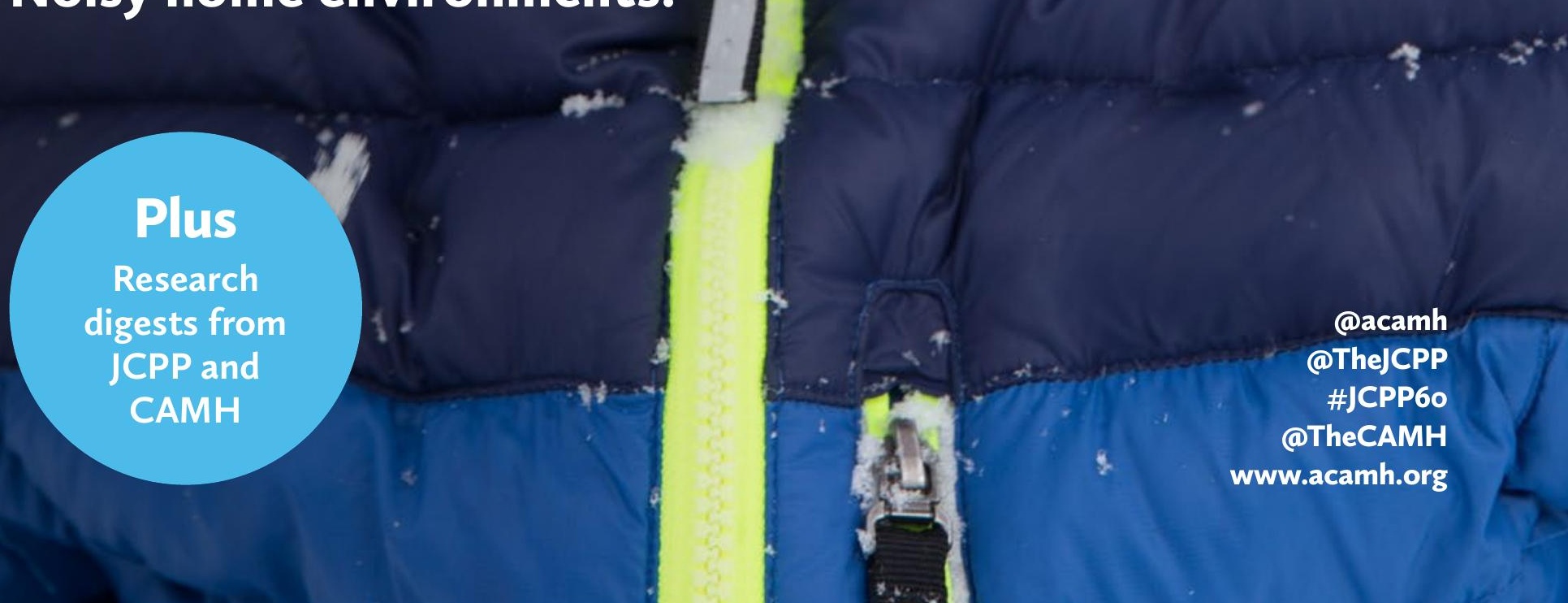


\section{Editorial}

The Bridge Editor, Dr Juliette Kennedy

Welcome to the December 2019 edition of The Bridge. It has been 2 years since The Bridge was relaunched in its current form. Each monthly themed edition publishes summaries of selected papers from the ACAMH journals - JCPP and CAMH - and occasionally features guest research digests. Over the past two years we have covered a huge range of topics (see index) and published over 170 research summaries and counting. These articles are usually accompanied with a glossary and a suggested reading list, which continue to produce a valuable education resource. What's more... it is available for free!

The 170 research digests in The Bridge have so far totalled over 52,000 page views. 2020 brings exciting plans to increase the reach of The Bridge to a wider audience and we will also continue to produce a monthly newsletter where you can sign-up to hear all of the latest 'The Bridge' news brought straight to your inbox, please sign up here: https://www.acamh.org/ newsletter-signup/.

In this edition we summarise a range of research papers that have been published in 2019: Alshaban et al. explore if parental consanguinity predicts the severity of Autistic symptoms; Ahmadzadeh et al. study the transmission of intergenerational anxiety in families; Mavranezouli et al's systematic review looks into the effectiveness of available interventions to treat PTSD in young people; Rimfeld et al's fascinating study explores the efficacy of teacher assessments vs exams to assess performance in schools in the UK; Stuart et al. study the relationship between intolerance of uncertainty and extreme demand avoidance (PDA) in young people with Autism; Wass et al. examine how fluctuations in external environmental noise affect the developing Autonomic Nervous System in babies.

I do hope you enjoy this edition and on behalf of all at The Bridge, I would like to wish you peace and joy for the festive season.

Do let us know your thoughts and comments by emailing - researchdigests@acamh.org.

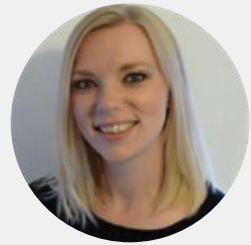

Research highlights in this edition are prepared by Dr Jessica K Edwards. Jessica is a freelance editor and science writer, and started writing for 'The Bridge' in December 2017.

\begin{tabular}{|c|c|}
\hline \multicolumn{2}{|c|}{ Index of past issues of The Bridge: } \\
\hline Dec 17: & General \\
\hline Jan 18: & ADHD \\
\hline Feb 18: & Informatics \\
\hline Mar 18: & Mental Health in Schools \\
\hline Apr 18: & Gender Identity \\
\hline May 18: & Attachment \\
\hline Jun 18: & Autism \\
\hline Jul 18: & Suicide and Self-Harm \\
\hline Aug 18: & Eating disorders \\
\hline Sep 18: & Depression \\
\hline Oct 18: & Forensic \\
\hline Nov 18: & Neurodevelopment \\
\hline Dec 18: & Anxiety \\
\hline Jan 19: & Sleep \\
\hline Feb 19: & Tourette Syndrome \\
\hline Mar 19: & Trauma \\
\hline Apr 19: & Conduct Disorders and Aggression \\
\hline May 19: & OCD \& ASD \\
\hline Jun 19: & $\begin{array}{l}\text { Depression, Self-harm and Suicidal } \\
\text { thoughts }\end{array}$ \\
\hline Jul 19: & Psychological resilience in young people \\
\hline Aug 19: & Neuroscience \\
\hline Sep 19: & Resilience \\
\hline Oct 19: & Suicide and Self-Harm \\
\hline Nov 19: & Parental Mental Illness \\
\hline Dec 19: & General \\
\hline
\end{tabular}




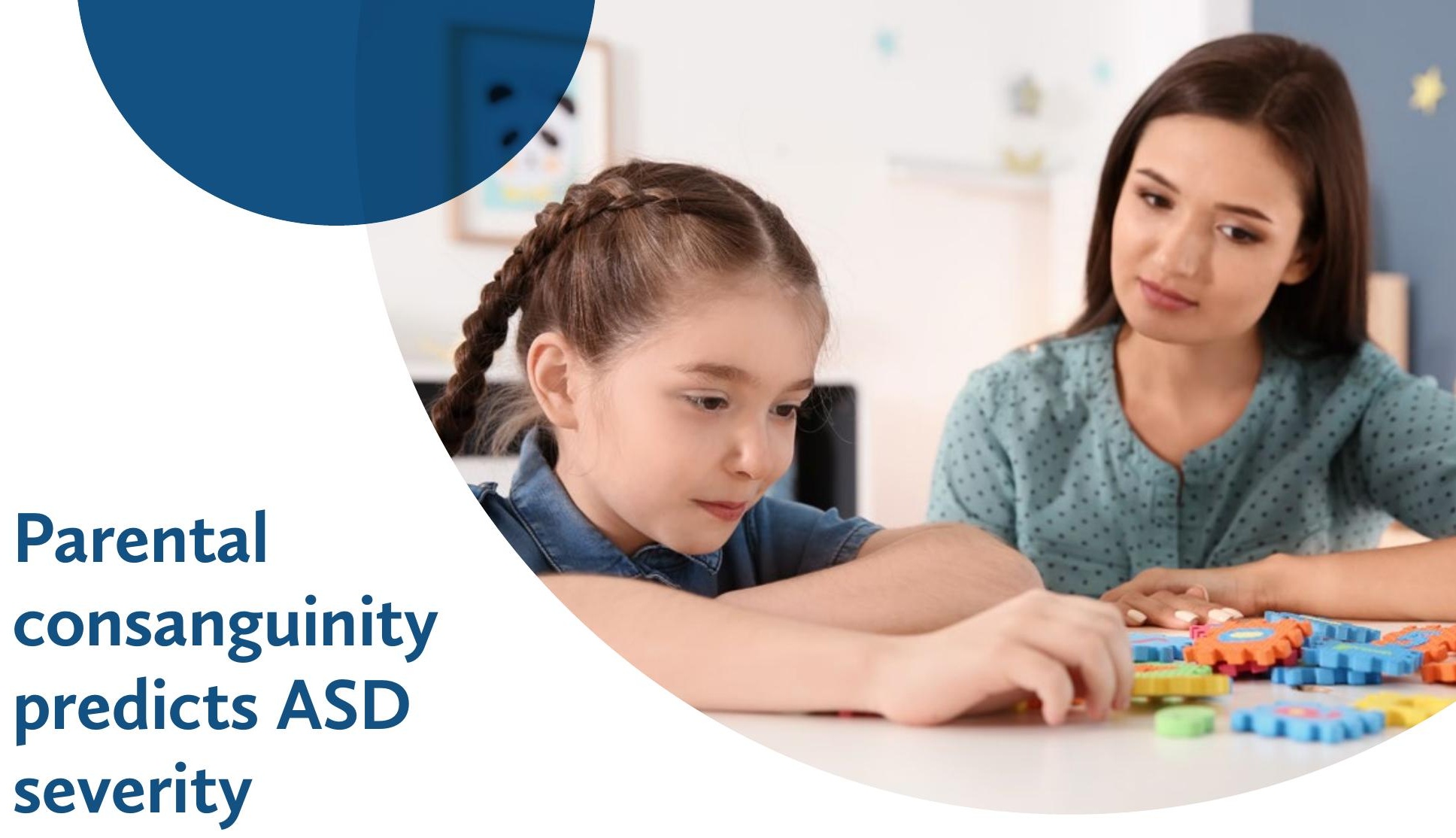

By Jessica K. Edwards

Earlier this year, Fouad Alshaban and colleagues screened a general school population to estimate the prevalence of autism spectrum disorder (ASD) in Qatar. The researchers identified 1,393 children from medical centres and special needs schools with diagnosed ASD. Then, they screened a further 9,074 children attending 93 different schools using the social communication questionnaire. ${ }^{1}$ After combining the datasets, the researchers identified that ASD prevalence in Qatar was $\sim 1.14 \%$ among children aged 6 -11 years old. While this reported ASD prevalence rate is in line with other recent international studies, ${ }^{2-4}$ it is much higher than the results of previous regional surveys. This difference might be due to the more comprehensive methodology used by the researchers to identify those affected by ASD. The level of parental consanguinity $(45 \%)$ in this cohort was also not significantly different from previously published rates for Qatar and other Arabian Peninsula countries. As such, the researchers conclude that parental consanguinity is unlikely to be a risk factor for ASD. Parental consanguinity could, however, predict ASD severity in this cohort after controlling for the effects of maternal health and developmental indicators. This striking finding suggests that the increased levels of allelic homozygosity in children of consanguineous parents might modulate ASD phenotypes. Other associations with ASD severity included gestational diabetes, delay in walking and developmental regression. Overall, the researchers estimate that 50,500 children $<5$ years-of-age and a further 137,000 children aged 5-19 years residing within the Arabian Peninsula have ASD. They hope that these figures will help guide health and educational service planning for young people in Qatar.
Referring to:

Alshaban, F., Aldosari, M., Al-Shammari, H., ElHag, S., Ghazal, I., Tolefat, M., Ali, M., Kamal, M., Aati, N.A., Abeidah, M., Saad, A.H., Dekair, L., Khasawneh, M.A., Ramsay, K. \& Fombonne, E. (2019), Prevalence and correlates of autism spectrum disorder in Qatar: a national study. J. Child Psychol. Psychiatr. doi: 10.111/jcpp.13066.

\section{References:}

${ }^{1}$ Rutter, M. et al. (2003), The Social Communication Questionnaire. Los Angeles: Western Pyscological Services.

${ }^{2}$ Arora, N.K. et al. (2018), Neurodevelopmental disorders in children aged 2-9 years: Populationbased burden estimates across five regions in India. PLoS Med. 15, e1002615. doi: 10.1371/journal. pmed.1002615.

${ }^{3}$ Baio, J. et al. (2018), Prevalence of autism spectrum disorder among children aged 8 years autism and developmental disabilities monitoring network, 11 Sites, United States, 2014. MMWR Surveill. Summ. 67, 1-23. doi: 10.15585/mmwr. ss6706al.

${ }^{4}$ Diallo, F.B., et al. (2018), Prevalence and correlates of autism spectrum disorders in Quebec. Can. J. Psychiatry 63, 231-239. doi: 10.1177/0706743717737031. 


\section{Child anxiety symptoms affect mothers via an environmental mechanism}

\section{By Jessica K. Edwards}

Intergenerational anxiety associations in families are well reported, ${ }^{1-3}$ but the underlying mechanisms of anxiety transmission are unclear. Now, researchers in the UK and the USA have conducted the first genetically sensitive study to explore the effects of genetic and environmental anxiety transmission in families during middle childhood. Using data from 305 families involved in the Early Growth and Development Study, ${ }^{4}$ Ahmadzadeh and colleagues measured anxiety symptoms in children (at ages 6, 7, and 8 years) and their adoptive and biological parents. Surprisingly, they found that child anxiety symptoms at age 7 prospectively predicted adoptive maternal, but not paternal, symptoms. The researchers also found preliminary evidence to support that anxiety in adoptive fathers could prospectively predict child anxiety symptoms from age 6 . This finding suggests that children are more susceptible to the effects of paternal than maternal anxiety symptoms. Finally, Ahmadzadeh et al. found no evidence for an association between birth family internalising problems (a proxy for inherited effects) and child anxiety symptoms. Taken together, this is the first study to show that intergenerational anxiety transmission can run from child-to-mother and father-to-child during middle childhood via an environmental mechanism. While further studies are now necessary to replicate these findings, the researchers hope that fathers will be included in family anxiety assessments and that the effects of child anxiety symptoms on caregivers will be considered.

\section{Referring to:}

Ahmadzadeh, Y.I., Eley, T.C., Leve, L.D., Shaw, D.S., Natsuaki, M.N., Reiss, D., Neiderhiser, J.M. \& McAdams, T.A. (2019), Anxiety in the family: a genetically informed analysis of transactional associations between mother, father and child anxiety symptoms. J. Child Psychol. Psychiatr. doi: 10.111/jcpp.13068.

\section{References:}

${ }^{1}$ Lawrence, P.J. et al. (2018). Systematic Review and meta-Analysis: Anxiety and Depressive Disorders in Offspring of Parents with Anxiety Disorders. J. Am. Acad. Child Adolesc. Psychiatry 58, 46-60. doi: 10.1016/j.jaac.2018.07.898.

${ }^{2}$ Micco, J.A. et al. (2009). Anxiety and depressive disorders in offspring at high risk for anxiety: A meta-analysis. J Anxiety Disord. 23, 1158-1164. doi: 10.1016/j.janxdis.2009.07.021.

${ }^{3}$ Sydsjo, G. et al. (2018). Anxiety in women - a Swedish national three-generational cohort study. BMC Psychiatry 18, 168. doi: 10.1186/s12888-0181712-0.

${ }^{4}$ Leve, L.D. et al. (2013). The Early Growth and Development Study: A prospective adoption study from birth through middle childhood. Twin Res. Hum. Genet. 16, 412-423. doi: 10.1017/thg.2012.126.

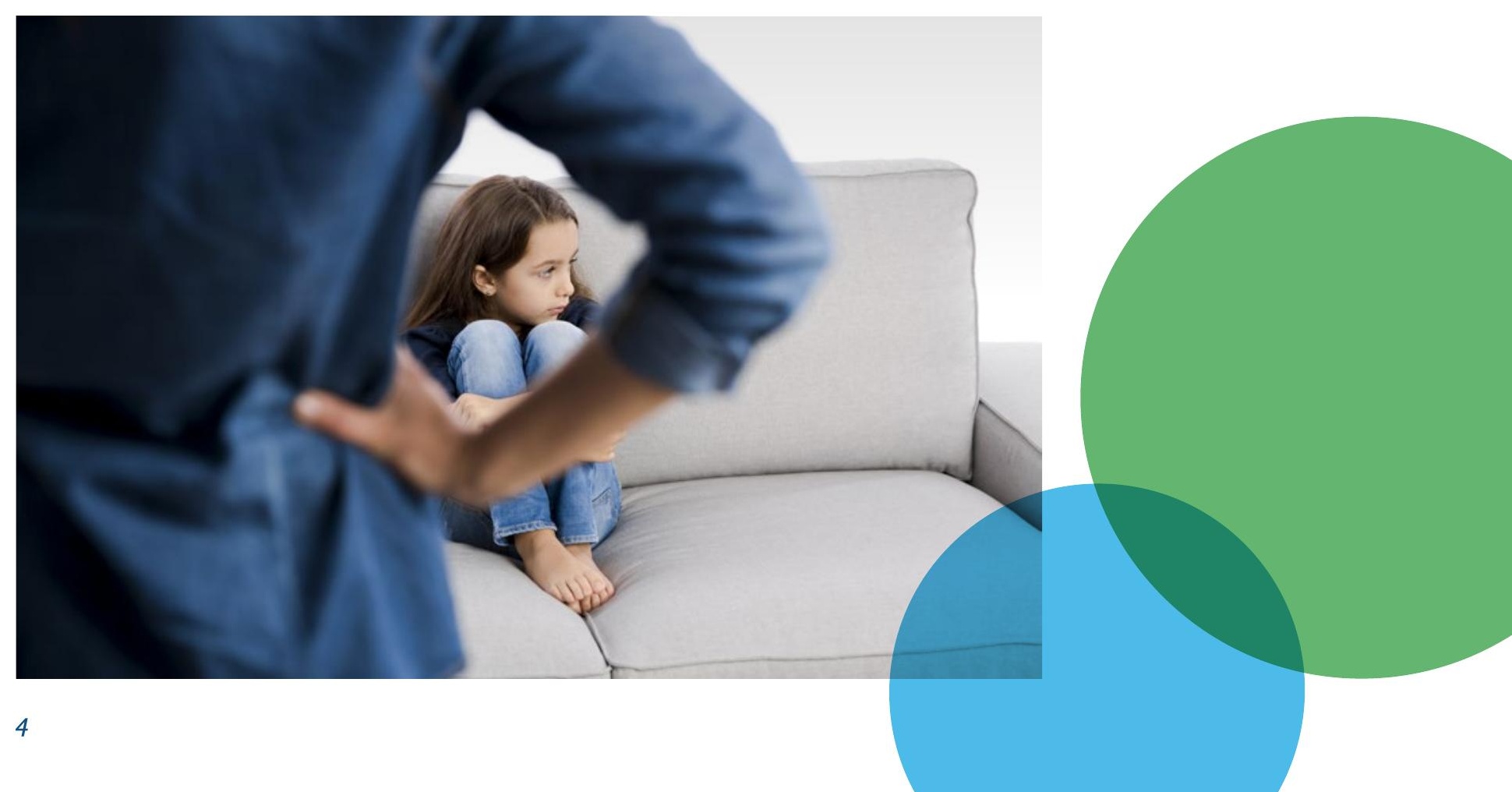




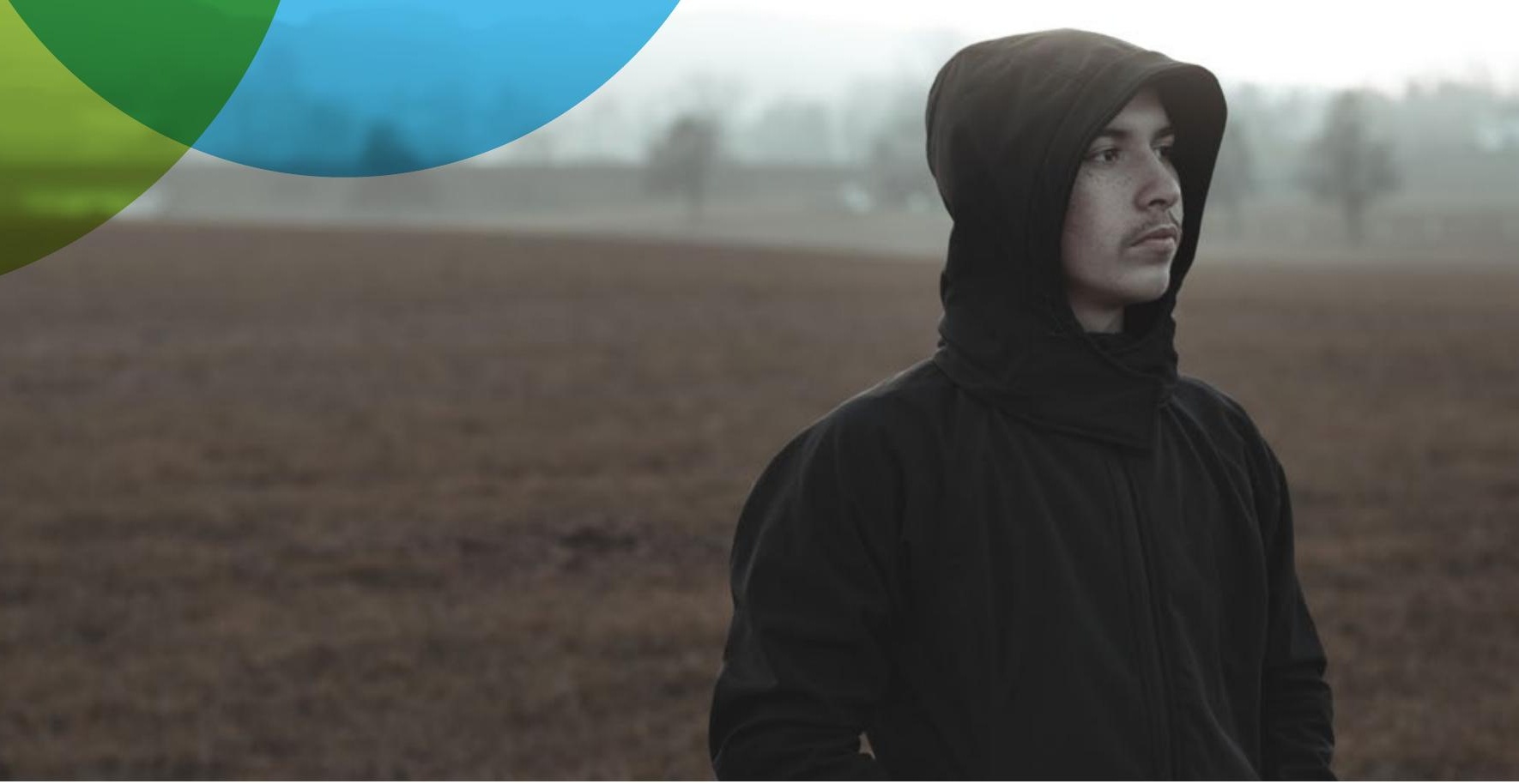

\title{
Supportive counselling is ineffective for managing PTSD in youth
}

\author{
By Jessica K. Edwards
}

More than half of children and young people are exposed to potentially traumatic events, ${ }^{1,2}$ and a significant minority of those exposed go on to develop post-traumatic stress disorder (PTSD). ${ }^{3}$ Because PTSD can be chronic, it can have a notable impact on child development, as well as social, academic and occupational function - it is therefore imperative that effective treatments are identified and prioritized. The current consensus is that trauma-focused cognitive behavioural therapy (TF-CBT) 4 is the most effective PTSD treatment, followed closely by eye movement desensitisation and reprocessing (EMDR). ${ }^{5}$ Many other treatments based on, for example, emotional freedom technique, child-parent psychotherapy, combined TF-CBT/parent training and meditation, have been proposed but their relative effectiveness has not been properly addressed.

In 2019, researchers in the UK performed a systematic review and network meta-analysis (NMA) of such psychological and psychosocial interventions for children and young people with PTSD. The implementation of this NMA approach meant that the researchers could make both direct and indirect treatment comparisons and thus estimate the relative effects of different treatments even if they were not directly compared in previous randomized controlled trials. ${ }^{6}$ The study included $\sim 2,000$ participants from 32 eligible studies that together assessed 17 interventions. The NMA allowed the researchers to rank PTSD interventions versus waitlist controls in terms of their descending magnitude of effect as follows: cognitive therapy for PTSD, combined somatic/cognitive therapies, child-parent psychotherapy, combined TFCBT/parent training, meditation, narrative exposure, exposure/prolonged exposure, play therapy, Cohen TF-CBT/cognitive processing therapy, EMDR, parent training, group TF-CBT, supportive counselling and family therapy.

'The researchers concluded that TF-CBT, particularly individual TF-CBT, is most effective for managing PTSD and achieving remission in affected youth.'

Based on the amount of evidence available for each treatment approach, the researchers concluded that TF-CBT, particularly individual TF-CBT, is most effective for managing PTSD and achieving remission in affected youth. Consistent with previous reports, they also found that EMDR seems to be effective, but to a lesser extent than TF-CBT. Most importantly, they found no significant difference between supportive counselling and waitlist controls, suggesting that this intervention should be avoided. Going forward, the researchers propose the routine use of TF-CBT for children and young people with PTSD, and EMDR as an alternative treatment option. Although emotional freedom technique, child-parent psychotherapy, combined TF-CBT/parent training, and meditation showed positive effects in reducing PTSD symptoms, further research is still required to determine their true efficacy. 


\section{Referring to:}

Mavranezouli, I., Megnin-Viggars, O., Daly, C., Dias, S., Stockton, S., Meiser-Stedman, R., Trickey, D. \& Pilling, S. (2019), Psychological and psychosocial treatments for children and young people with post-traumatic stress disorder: a network meta-analysis. J. Child Psychol. Psychiatr. doi: 10.111/jcpp.13094.

\section{Glossary:}

Post-traumatic stress disorder (PTSD): PTSD is included in the DSM-5 chapter on Trauma- and Stressor-Related Disorders. The trigger to PTSD is defined as exposure to actual or threatened death, serious injury or sexual violation. The individual may be exposed to the event directly or witness the event, learn of a traumatic event that occurred to a close family member or close friend, or experience first-hand repeated or extreme aversive details of a traumatic event. The disturbance, regardless of its trigger, causes clinically significant distress or impairment in the individual's social interactions, capacity to work or other important areas of functioning. It is not the physiological result of another medical condition, medication, drugs or alcohol.

\section{Trauma-focused cognitive behavioural therapy}

(TF-CBT): a form of CBT that is specifically adapted for PTSD. This short-term intervention typically requires between eight and 25 sessions, and uses cognitive behavioural techniques to modify distorted or unhelpful thinking and negative reactions and behaviours.

\section{Eye movement desensitization and reprocessing:} a brief, trauma-focused treatment whereby the patient visualizes a disturbing image from the trauma in their memory while engaging in sets of saccadic eye movements. These rapid eye movements are intended to create a similar effect to the way the brain processes memories and experiences during sleep. In this way, the brain appropriately re-processes distressing memories and eliminates emotional distress.

Network meta-analysis: a meta-analysis where more than three treatments are compared by both directly comparing the interventions within randomized controlled trials and by indirectly comparing the interventions across trials based on a common comparator or control group. This approach can answer more relevant clinical questions and can make treatment estimates for an entire treatment network than multiple, separate pair-wise analyses.

\section{References:}

${ }^{1}$ Landolt, M.A. et al. (2013), Trauma exposure and posttraumatic stress disorder in adolescents: a national survey in Switzerland. J. Trauma Stress. 26, 209-216. doi: 10.1002/jts.21794.

${ }^{2}$ McLaughlin, K.A. et al. (2013), Trauma exposure and posttraumatic stress disorder in a national sample of adolescents. J. Am. Acad. Child Adolesc. Psychiatry. 52, 815-830. doi: 10.1016/j/ jaac.2013.05.011.

${ }^{3}$ Alisic, E. et al. (2014), Rates of posttraumatic stress disorder in trauma-exposed children and adolescents: Meta-analysis. Br. J. Psychiatry. 204, 335-340. doi: 10.1192/bjp.bp.113.131227

${ }^{4}$ Cohen, J. A., Mannarino, A. P. \& Deblinger, E. (2017). Treating Trauma and Traumatic Grief in Children and Adolescents (2nd Ed.).: New York, NY: Guilford.

${ }^{5}$ Shapiro, F. et al. (2014), The Role of Eye Movement Desensitization and Reprocessing (EMDR) Therapy in Medicine: Addressing the Psychological and Physical Symptoms Stemming from Adverse Life Experiences. Perm. J. 18: 71-77. doi: 10.7812/TPP/13-098.

${ }^{6} \mathrm{Lu}, \mathrm{G}$. et al. (2004), Combination of direct and indirect evidence in mixed treatment comparisons. Stat. Med. 23, 3105-3124. doi: 10.1002/sim.1875 


\title{
Teacher assessments could replace high- stake testing to improve student well-being
}

\author{
By Jessica K. Edwards
}

Children in the UK must complete numerous standardized school exams and teacher-based assessments during their compulsory education. Despite the known benefits of testing in terms of consolidating and fostering learning, there are many known downsides to regular testing. For example, many students experience anxiety and distress during exams, and these emotions can have a negative effect on achievement. Notably, one of the top-reported concerns voiced by children in the UK is the stress and anxiety associated with school work and exam performance. ${ }^{1}$

Now, Kaili Rimfeld and colleagues have assessed the cost-benefit ratio for standardized exams and teacher assessments in school-age children. They examined the phenotypic and genetic associations between teacher assessments and standardized exam scores at ages 7,11 and 14, and then assessed the extent to which standardized test scores add to teacher assessments and help predict educational achievement in key subjects at ages 16 and 18 . Their study included $>5,000$ twin pairs enrolled in the UK-representative Twins Early Development Study who were studied longitudinally from age 7 to 18 . They found that teacher assessments of achievement were as reliable, stable and heritable $(\sim 60 \%)$ as test scores at every stage of education. Furthermore, teacher and exam test scores showed a strong correlation both phenotypically and genetically ( 0.7). Most notably, teacher assessments predicted $\sim 90 \%$ of the differences between pupils in exam performance at ages 16 and 18 .
The researchers consider that their data might inform the debate on the use of high-stake examining during compulsory school education in the UK. Specifically, the high correlation between teacher assessments and test scores raises the question as to the value of compulsory testing in the UK, culminating in high-stake exams at age 16 (GCSEs) and 18 (A-levels). Because of the various costs of high-stake examining, the researchers promote the standardization and wider use of teacher assessments and a reduction in testing to help improve student well-being.

\section{Referring to:}

Rimfeld, K., Malanchini, M., Hannigan, L.J., Dale, P.S., Allen, R., Hart, S.A. \& Plomin, R. (2019),

Teacher assessments during compulsory education are as reliable, stable and heritable as standardized test scores. J. Child Psychol. Psychiatr. doi: 10.111/ jcpp.13070.

\section{See also: www.teds.ac.uk/}

\section{References:}

${ }^{1}$ NSPCC (2015) Under pressure: Childline annual review 2013/2014. London: NSPCC. 


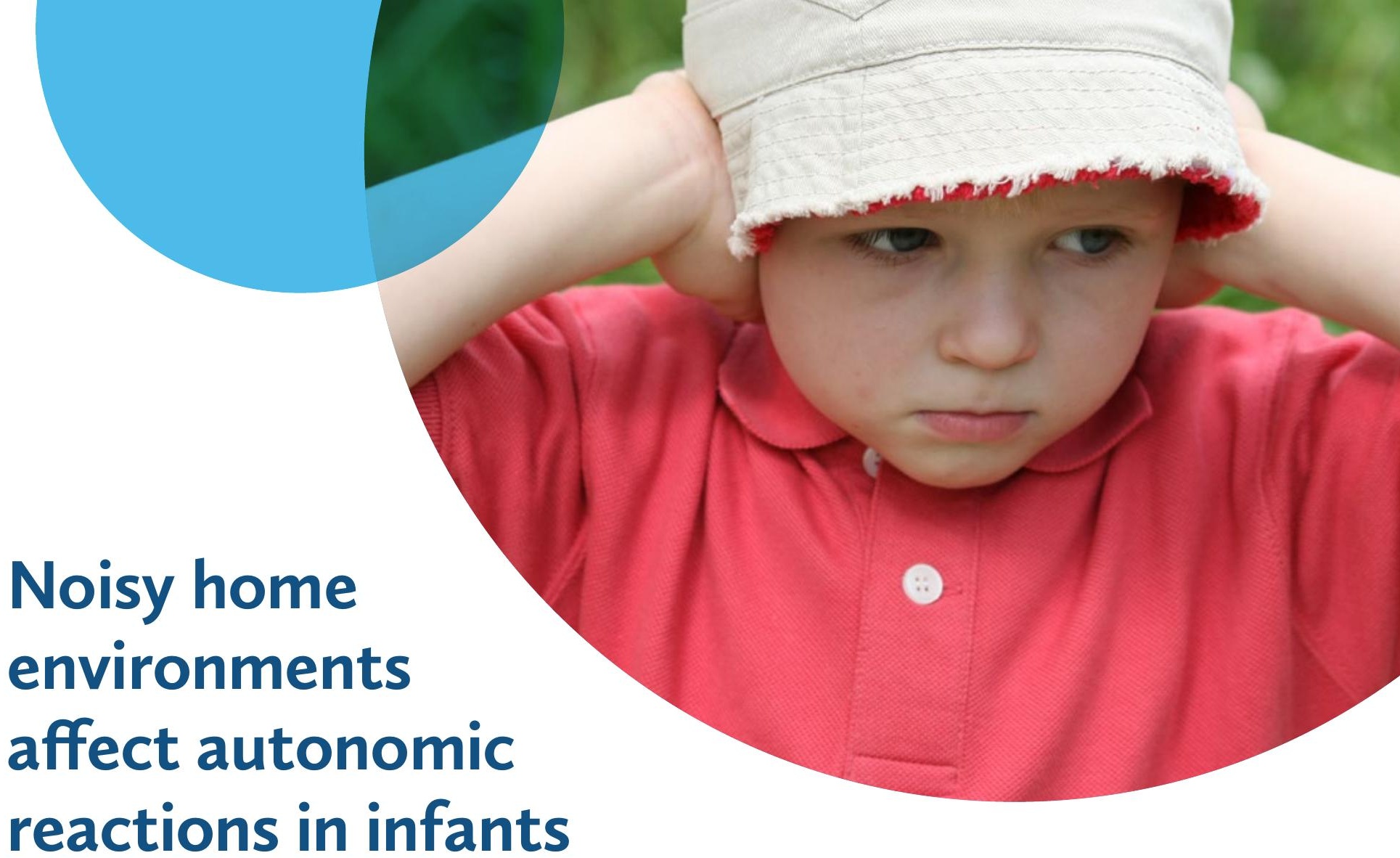

\section{By Jessica K. Edwards}

Previous research has suggested that children who are exposed to a stressful environment early in life are at a higher risk of adverse long-term outcomes, including mental disorders ${ }^{1}$ and cognitive impairment. ${ }^{2}$ Now, a team of researchers in the UK have monitored autonomic reactions in 82 infants aged 12 months old in response to noise in the home environment, to better understand the mechanisms underlying this risk. The infants were monitored over 1 day using devices that measured heart rate and rest/activity cycles to determine the degree of autonomic arousal, alongside microphones that recorded environmental noise. Then, the infants underwent a battery of laboratory tests to assess attention and emotional response to various stimuli. The researchers found that infants exposed to higher and more rapidly fluctuating environmental noise in the home, showed more unstable autonomic arousal patterns, compared to those exposed to quieter home noise environments. These affected infants also showed labile and short-lived autonomic changes in response to novel attention-eliciting stimuli, reduced sustained visual attention and increased arousal lability in response to an emotional stressor. The researchers concluded that children exposed to more noisy environments showed reduced autonomic responsiveness to novel stimuli and more fast-changing profiles of autonomic arousal. For the first time, they examined how fluctuations in external environmental noise affect the developing Autonomic Nervous System. The researchers believe that these findings help explain how stressful environments might adversely affect long-term affective and cognitive outcomes.

Referring to:

Wass, S.V., Smith, C.g., Daubney, K.R., Suata, Z.M., Clackson, K., Begum, A. \& Mirza, F.U. (2019), Influences of environmental stressors on autonomic function in 12-month-old infants: understanding early common pathways to atypical emotion regulation and cognitive performance. J. Child Psychol. Psychiatr. doi: 10.111/jcpp.13084.

\section{References:}

${ }^{1}$ Businelle, M.S. et al. (2013), Do stressful events account for the link between socioeconomic status and mental health? J. Pub. Health (Oxf). 36, 205-212. doi: 10.1093/pubmed/fdto6o.

${ }^{2}$ Blair, C. (2010), Stress and the Development of Self-Regulation in Context. Child Dev. Perspect. 4, 181-188. doi: 10.1111/j.1750-8606.2010.00145.x. 